\title{
Family structure and risk factors for schizophrenia: case-sibling
} study

\author{
Jari K Haukka*, Jaana Suvisaari and Jouko Lönnqvist
}

Address: Department of Mental Health and Alcohol Research, KTL, National Public Health Institute, Mannerheimintie 160, FIN-00300 Helsinki, Finland

Email: Jari K Haukka* - jari.haukka@ktl.fi; Jaana Suvisaari - jaana.suvisaari@ktl.fi; Jouko Lönnqvist - jouko.lonnqvist@ktl.fi

* Corresponding author

Published: 27 November 2004

BMC Psychiatry 2004, 4:4I doi:| 0.| | 86/|47|-244X-4-4|
Received: 12 March 2004

Accepted: 27 November 2004

This article is available from: http://www.biomedcentral.com/I47I-244X/4/4I

(C) 2004 Haukka et al; licensee BioMed Central Ltd.

This is an Open Access article distributed under the terms of the Creative Commons Attribution License (http://creativecommons.org/licenses/by/2.0), which permits unrestricted use, distribution, and reproduction in any medium, provided the original work is properly cited.

\begin{abstract}
Background: Several family structure-related factors, such as birth order, family size, parental age, and age differences to siblings, have been suggested as risk factors for schizophrenia. We examined how family-structure-related variables modified the risk of schizophrenia in Finnish families with at least one child with schizophrenia born from 1950 to 1976.
\end{abstract}

Methods: We used case-sibling design, a variant of the matched case-control design in the analysis. Patients hospitalized for schizophrenia between 1969 and 1996 were identified from the Finnish Hospital Discharge Register, and their families from the Population Register Center. Only families with at least two children (79/4 sibships and 21059 individuals) were included in the analysis. Conditional logistic regression with sex, birth cohort, maternal schizophrenia status, and several family-related variables as explanatory variables was used in the case-sibling design. The effect of variables with the same value in each sibship was analyzed using ordinary logistic regression.

Results: Having a sibling who was less than five years older (OR I.46, 95\% Cl I.29-I.66), or being the firstborn (first born vs. second born 1.62, I.87-I.4) predicted an elevated risk, but having siblings who were more than ten years older predicted a lower risk $(0.66,0.56-0.79)$.

Conclusions: Several family-structure-related variables were identified as risk factors for schizophrenia. The underlying causative mechanisms are likely to be variable.

\section{Background}

Several factors relating to family structure have been suggested as risk factors for schizophrenia. They include sibship size, number of older siblings, birth order in the sibship, age difference to older siblings, and age-at-onset, and sex of the affected siblings. These family-related risk factors may provide useful hints about the nature of environmental and genetic risk factors for schizophrenia [1].
In several studies, siblings of female probands have had a higher risk of developing schizophrenia than siblings of male probands in several studies, with the number of cases varying from 123 to 500 [2-7]. The effect of the ageat-onset of proband is less clear. Some studies have detected no effect $[5,8]$, but in one, early age-at-onset of proband predicted a higher risk for siblings [4].

There are mixed results about the effect of birth order on risk. Two studies reported lowest risk for the firstborns 
$[9,10]$, and in a Swedish population based study with 167 cases, male subjects fourth or higher in birth order had over a three-fold risk compared to males with lower birth order [11]. On the other hand, a very large scale Danish cohort study involving 2669 cases showed no effect for birth order [12]. A significantly higher risk for first-born males was reported from a Finnish cohort study with 100 cases [13], and in accordance with this, a recent study from Pakistan with 453 cases reported highly significant excess of firstborns among patients with schizophrenia [14].

The number and age of older siblings at the time of birth is hypothesized to be connected to the risk of schizophrenia through infection pressure. In a Swedish registerbased study (270 cases), having siblings who were 3-4 years older was associated with increased risk (relative was 2.02) [10]. The Danish cohort showed no effect of birth order on risk, but found that having less than two years age difference to the nearest older or younger sibling increased the risk of schizophrenia [12]. However, in an Irish case-control study with 2969 cases and 5904 controls, the number of older siblings did not predict a diagnosis of schizophrenia over neurosis [15]. Several recent studies have found that advanced paternal age is a risk factor for schizophrenia [16-18].

All risk factors concerning birth order, family size, number of older or younger siblings, and paternal and maternal age are correlated. For example, the number of older siblings is dependent on both the individual's birth order and family size, which are connected to maternal age. If all these correlated variables are not in the model simultaneously, spurious associations may be found. Therefore, a large, population-based data set that contains a sufficient number of sibships with variable structures is needed to analyze family-related variables. Our aim was to investigate which of these variables were risk factors for schizophrenia in Finland among those who were born between 1950 and 1976.

\section{Methods}

\section{Register data, study design and statistical analyses}

Using the Finnish Hospital Discharge Register of Finland, we obtained information on all hospitalizations with a diagnosis of schizophrenia (ICD-8 295*, ICD-9 295*, ICD-10 F20*). The information was sought for all Finns born between 1950 and 1976 for the period between 1969 and 1996. Sibship was defined as a group of individuals having the same mother. Since many of the variables we examined are related to maternal characteristics, we considered it essential that each sibship has the same mother. It should be noticed that generally the mother has a stronger influence on the child than the father especially in early childhood: e.g. mother's womb provides the fetal environment, and after birth the mother has more of a close physical relationship to the child through breast feeding. Siblings and parents of the probands were identified using the data from the Population Register Centre, and their information was then linked back to the Hospital Discharge Register to obtain data on relatives' hospitalizations. Only those who were born between 1950 and 1976 were qualified as probands, but their younger siblings were included in analyses as family members.

We assumed our ascertainment was complete, because the two registers used, the Population Register and the Finnish Hospital Discharge Register, are nationwide and accurate [19]. The reliability of register diagnoses of schizophrenia is good [20-22] and according to previous studies, more than 95 percent of individuals with schizophrenia receive hospital treatment at some point in their lives [22].

Altogether, we identified 17549 sibships with 35481 siblings, of whom 31004 were born between 1950 and 1976 . There were 12 siblings in the largest family, and the highest number of cases in one family was six (Table 3). All families that contained only one child $(\mathrm{n}=7947)$ were excluded from the study because almost all variables we investigated required there to be more than one child in the family.

Table 3: A family study of schizophrenia in Finland in birth cohorts born from 1950 to 1976. Family structure of families ( $\mathrm{N}=2605)$ with at least one sibling with schizophrenia; also siblings born before 1950 and after 1976 are included.

\begin{tabular}{|c|c|c|c|c|c|c|c|c|c|c|c|}
\hline \multirow{2}{*}{$\begin{array}{l}\text { N. of cases } \\
\text { in the } \\
\text { family }\end{array}$} & \multicolumn{11}{|c|}{ Family size } \\
\hline & 2 & 3 & 4 & 5 & 6 & 7 & 8 & 9 & 10 & 11 & 12 \\
\hline I & 3289 & 2012 & 984 & 369 & $17 \mid$ & 62 & 22 & 9 & 5 & I & 0 \\
\hline 2 & 282 & 271 & 190 & 82 & 35 & 16 & 12 & 5 & 1 & 0 & 0 \\
\hline 3 & 0 & 22 & 26 & 11 & 10 & 8 & 4 & 0 & 1 & 0 & I \\
\hline 4 & 0 & 0 & 4 & 2 & 1 & I & I & 0 & 0 & 0 & 0 \\
\hline 5 & 0 & 0 & 0 & I & 0 & I & 0 & 0 & 0 & 0 & 0 \\
\hline 6 & 0 & 0 & 0 & 0 & 0 & 0 & I & 1 & 0 & 0 & 0 \\
\hline
\end{tabular}


We used two types of explanatory variables: variables that were unique for each person, and variables that had the same value for all members of the sibship. The unique variables were sex, birth cohort, birth order, number and ages of older siblings at the time of birth, and the age of mother and father at the time of birth, and the shared variables were the lowest age-at-onset in sibship, sex of the proband with lowest age-at-onset in the sibship, and the sibship size, and whether the mother had schizophrenia or not.

\section{Study design and statistical analyses}

We investigated the effect of unique variables using the case-sibling design [23], in which each case was matched with one or more unaffected siblings. We modeled the data with conditional logistic regression using each case in the family as the conditioning unit, which is the standard method for case-sibling design [23].

The sibling with the lowest age-at-onset of schizophrenia was the first case or proband and all unaffected siblings born between 1950 and 1976 and alive at age when first sibling had his/her first illness episode, were chosen as controls. Thus, the matching was carried out with respect to age-at-onset. If there were later cases in the family, controls were chosen in the same way but excluding those siblings who already had developed schizophrenia. Thus, a sibling could serve as a control before developing schizophrenia. The number of cases with at least one control was 9013 and the number of controls was 12046. As shown in Table 4, our data included a substantial number of families with more than 5 siblings.

Table 4: Basic characteristics of sibships.

\begin{tabular}{|c|c|c|c|c|c|c|}
\hline \multirow{2}{*}{ Sex } & \multirow[b]{2}{*}{ male } & \multicolumn{2}{|c|}{ no schizophrenia (\%) } & \multicolumn{2}{|c|}{ schizophrenia (\%) } & \multirow{2}{*}{$\begin{array}{r}\text { All } \\
9843\end{array}$} \\
\hline & & 4636 & 47 & 5207 & 52 & \\
\hline & female & 7410 & 66 & 3806 & 34 & 11216 \\
\hline \multirow[t]{2}{*}{ Siblings under 5 years } & no & 5496 & 52 & 4876 & 48 & 10372 \\
\hline & yes & 6550 & 61 & 4137 & 39 & 10687 \\
\hline \multirow[t]{2}{*}{ Siblings 5- 10 years } & no & 7727 & 52 & 7172 & 48 & 14899 \\
\hline & yes & 4319 & 70 & $184 \mid$ & 30 & 6160 \\
\hline \multirow[t]{2}{*}{ Siblings over 10 years } & no & 10094 & 55 & 8377 & 45 & |847| \\
\hline & yes & 1952 & 75 & 636 & 25 & 2588 \\
\hline \multirow[t]{4}{*}{ Birth order } & I & 2934 & 44 & 3781 & 56 & 6715 \\
\hline & 2 & 4297 & 57 & 3260 & 43 & 7557 \\
\hline & 3 & 2629 & 68 & 1262 & 32 & 3891 \\
\hline & $4+$ & 2186 & 75 & 710 & 25 & 2896 \\
\hline \multirow[t]{4}{*}{ Birth cohort } & $1950-1955$ & 3756 & 51 & 3648 & 49 & 7404 \\
\hline & $1956-1960$ & 3566 & 57 & 2689 & 43 & 6255 \\
\hline & $1961-1965$ & 2825 & 62 & 1748 & 38 & 4573 \\
\hline & $1966-1976$ & 1899 & 67 & 928 & 33 & 2827 \\
\hline \multirow[t]{5}{*}{ Maternal age } & under 20 & $44 I$ & 45 & 546 & 55 & 987 \\
\hline & $20-25$ & 2509 & 50 & 2462 & 50 & 4971 \\
\hline & $26-30$ & 3419 & 56 & 2692 & 44 & 6111 \\
\hline & $31-35$ & 2896 & 62 & 1778 & 38 & 4674 \\
\hline & over 35 & 2781 & 64 & 1535 & 36 & 4316 \\
\hline \multirow[t]{6}{*}{ Paternal age } & under 20 & 101 & 49 & 106 & 51 & 207 \\
\hline & $20-25$ & $128 \mid$ & 49 & 1355 & 51 & 2636 \\
\hline & $26-30$ & 2727 & 53 & 2413 & 47 & 5140 \\
\hline & $31-35$ & 2765 & 60 & 1879 & 40 & 4644 \\
\hline & over 35 & 4159 & 63 & 2407 & 37 & 6566 \\
\hline & not available & 1013 & 54 & 853 & 46 & 1866 \\
\hline \multirow[t]{2}{*}{ Sex of youngest proband } & male & 6880 & 57 & 5187 & 43 & 12067 \\
\hline & female & 5166 & 57 & 3826 & 43 & 8992 \\
\hline \multirow[t]{4}{*}{ Lowest age-at-onset in sibship } & under 20 & 2797 & 54 & 2351 & 46 & 5148 \\
\hline & $20-25$ & 4410 & 57 & 3350 & 43 & 7760 \\
\hline & $26-30$ & 2930 & 59 & 2014 & 41 & 4944 \\
\hline & over 30 & 1909 & 60 & 1298 & 40 & 3207 \\
\hline \multirow[t]{4}{*}{ Family size } & 2 & 3623 & 46 & 4233 & 54 & 7856 \\
\hline & 3 & 3623 & 59 & 2551 & 41 & 6174 \\
\hline & 4 & 2373 & 65 & 1284 & 35 & 3657 \\
\hline & $5+$ & 2427 & 72 & 945 & 28 & 3372 \\
\hline \multirow[t]{2}{*}{ Mother schizophrenic } & no & 11537 & 57 & 8561 & 43 & 20098 \\
\hline & yes & 509 & 53 & 452 & 47 & 961 \\
\hline
\end{tabular}


Table 2: The effect of shared family-related variables on siblings' odds of developing schizophrenia: results from the multivariate logistic regression where the proband was removed from the analysis, odds ratios with $95 \%$ confidence intervals. Unique family-related variables (sex, ages of other siblings, birth order, birth cohort, maternal age, and paternal age) were also included in models as background variables.

\begin{tabular}{ll}
\hline $\begin{array}{l}\text { Sex of the youngest proband (female vs. male) } \\
\text { Lowest age-at-onset in the sibship }\end{array}$ & $0.983(0.864,1.117)$ \\
under 20 & $($ reference $)$ \\
$20-25$ & $0.574(0.497,0.664)$ \\
$26-30$ & $0.323(0.267,0.391)$ \\
over 30 & $0.156(0.116,0.209)$ \\
Family size & $($ reference) \\
2 & $1.128(0.943,1.349)$ \\
3 & $1.282(1.043,1.575)$ \\
4 & $1.286(1.019,1.623)$ \\
$5+$ & $1.822(1.431,2.321)$ \\
Mother schizophrenic(no vs. yes) &
\end{tabular}

birth cohorts, primiparity was a risk factor for having a low birth weight infant and for perinatal mortality [24]. In an earlier Finnish cohort study, infants of multiparous women were significantly heavier than infants of primiparous women [25]. As low birth weight and some obstetric complications increase the risk of later development for schizophrenia [26], they may explain the increased risk of schizophrenia among the firstborns. Having siblings who were less than five years older was a risk factor for schizophrenia in our study. Sham et al. found that having siblings who were 3-4 years older was a risk factor for schizophrenia [10], while Westergaard et al. found that a short interval to the nearest older sibling was a risk factor for schizophrenia [12]. Both suggested that common infections brought to the family by young siblings, causing fetal or early childhood infections, could lie behind the association $[10,27]$. Consistently with this, Brown et al found in a cohort study that second trimester exposure to respiratory infections increased the risk of later development of schizophrenia spectrum disorders two-fold [28].

\section{Discussion}

Our results concerning the effect of paternal and maternal age are not comparable to previous studies [16-18], because all patients who did not have siblings were excluded from the analysis. Our findings suggest that in families with at least two children, young maternal age at birth is a risk factor for schizophrenia. This could be linked to obstetric complications. However, although some studies have found that obstetric complications are more common among adolescent mothers [29], this is not the case in Finland [24,30]. Thus, obstetric complications probably do not explain why the offspring of young mothers have an increased risk of schizophrenia.
Consistently with a recent meta-analysis [31], the risk of schizophrenia was 50 percent lower for females than males. If risk factors for schizophrenia are equally distributed among females and males but females are for some reason more resilient to them, it could be assumed that females who develop schizophrenia have more schizophrenia-predisposing genes than males. This would explain why siblings' risk of schizophrenia was higher when the proband was female.

Our results showed that the higher was the age-at-onset of the first proband in the family, the lower was the siblings' risk (Tables 1 and 2), which is in line with previous family studies $[5,32,33]$ and also with studies that found an earlier age-at-onset among patients with familiar rather than sporadic schizophrenia [34]. Also, a study of parents of patients with childhood- and adult-onset schizophrenia found that parents of patients with childhood-onset schizophrenia had a significantly higher morbid risk of schizophrenia spectrum disorders than parents with adult-onset schizophrenia [35]. All these findings are consistent with the hypothesis that in schizophrenia, as in many other multifactorial neuropsychiatric diseases [36], early age at onset is a marker of greater genetic vulnerability to the disorder.

A case-sibling design has some limitations. It can only provide approximate estimates of relative risk. In our analyses only families with two or more siblings were informative, and therefore our results are not applicable to one child families. However, whether matching was taken into account or not did not largely affect the results.

Our study was based on a nationwide, representative sample of patients with schizophrenia and their siblings, and 
our sample size was considerably larger than in any of the previous studies. Register-based information is not as accurate as information based on face-to-face interview, but Finnish registers are quite reliable. The two registers we used, the National Population Register and the National Hospital Discharge Register, are nationwide. The National Hospital Discharge Register covers all public and private hospitals in Finland, and the National Population Register registers all Finnish citizens. However, as information on parents enabling the identification of sibships first appeared in the Population Register only in 1974, sibship data may be more accurate in the younger cohorts. Information in both registers is accurate. Some proportion of siblings of the study population are really half-siblings, but even in this case, the case-sibling design is applicable, because it does not assume that familial aggregation is due to a genetic mechanism. When entries in the National Hospital Discharge Register were compared with data on hospital case notes, the primary diagnosis in the register and hospital case notes was identical in 99 percent of cases for schizophrenia and in 98 percent of cases for all mental disorders [19]. The reliability of register diagnoses of schizophrenia is also good, with a greater propensity for false-negatives than false-positives [20-22,37].

\section{Conclusions}

We investigated concurrently several family-related factors which independently have been suggested to be risk factors for schizophrenia. We were able to verify some of the previous associations, while others were refuted. The risk factors we identified probably have different underlying causative mechanisms. For example, the risk associated with being the firstborn might be explained by increased risk to obstetric complications, while the combination of decreased risk among females but increased risk among siblings of female probands might be explained by genetic factors. The risk factors we identified should be studied further in samples that include more detailed information on possible causative factors, such as infections and obstetric complications.

\section{Competing interests}

The author(s) declare that they have no competing interests.

\section{Authors contributions}

$\mathrm{JH}$ participated in the design of the study, performed the data-analysis and drafted the manuscript. JS participated in the design of the study, and the drafting of the manuscript. JL participated in the design of the study and its coordination. All authors read and approved the final manuscript.

\section{References}

I. Castle D, Abel K, Takei N, Murray RM: Gender differences in schizophrenia: hormonal effect or subtypes. Schizophrenia Bulletin 1995, 2 I: I-12.

2. Goldstein JM, Faraone SV, Chen WJ, Tolomiczencko GS, Tsuang MT: Sex differences in the familial transmission of schizophrenia. British Journal of Psychiatry 1990, I 56:819-26.

3. Goldstein JM, Faraone SV, Chen WJ, Tsuang MT: Gender and the familial risk for schizophrenia. Schizophrenia Research 1992, 7:135-140.

4. Goldstein JM, Faraone SV, Chen WJ, Tsuang MT: The role of gender in understanding the familial transmission of schizoaffective disorder. British Journal of Psychiatry 1993, I 63:763-768.

5. Maier W, Lichterman D, Heun R, Hallmayer J: The impact of gender and age at onset on the familial aggregation of schizophrenia. Eur Arch Clin Neurosci 1993, 242:279-285.

6. Sham P, Jones P, Russell A, Gilvarry K, Bebbington P, Lewis S, Toone $B$, Murray R: Age at onset, sex, and familial psychiatric morbidity in schizophrenia. British Journal of Psychiatry 1994, 1 65:466-473.

7. Kendler KS, Walsh D: Gender and schizophrenia. British Journal of Psychiatry 1995, I67: I84-192.

8. Kendler K, Tsuang MT, Hays P: Age at onset in schizophrenia. Archives General Psychiatry 1987:881-890.

9. Hare EH, Price JS: Birth rank in schizophrenia: with a consideration of the bias due to changes in birth-rate. British Journal of Psychiatry 1970, I 1 6:409-420.

10. Sham PS, MacClean CJ, Kendler KS: Risk of schizophrenia and age difference with older siblings. British Journal of Psychiatry 1993, 1 63:627-633.

II. Hultman CM, Sparen P, Takei N, Murray RM, Cnattingius S: Prenatal and perinatal risk factors for schizophrenia, affective psychosis, and reactive psychosis of early onset: case-control study. BJM 1999, 3 I 8:42 I-426.

12. Westergaard T, Mortensen P, Pedersen C, Wohlfahrt J, Melbye M: Exposure to prenatal and childhood infections and the risk of schizophrenia. Archives General Psychiatry 1999, 56:993-998.

13. Kemppainen L, Veijola J, Jokelainen J, Hartikainen $A L$, Järvelin $M R$, Jones $\mathrm{P}$, Croudace T, Isohanni M: Birth order and risk for schizophrenia: a 31 -year follow-up of the Northern Finland 1966 birth cohort. Acta Psychiatrica Scandinavica 200 I, I 04: I48-I 52.

14. Bender KG, Azeem N, Morrice J: Schizophrenia and birth order in Pakistan. Schizophrenia Research 2000, 44: I I3-1 20.

15. McDonald C, O'Callaghan E, Keogh F, Sham P, Kinsella A, Morris M, Walsh D: Number of older siblings of individuals diagnosed with schizophrenia. Schizophr Res 2001, 47:275-280.

16. Malaspina D, Harlap S, Fennig S, Heiman D, Nahon D, Feldman D, Susser $E$ : Advancing paternal age and the risk of schizophrenia. Archives General Psychiatry 200I, 58:36I-367.

17. Dalman C, Allebeck P: Paternal age and schizophrenia: further support for an association. American Journal of Psychiatry 2002, I59:I59|-I592.

18. Brown AS, Schaefer CA, Wyatt RJ, Begg MD, Goetz R, Bresnahan MA, Harkavy-Friedman J, Gorman JM, Malaspina D, Susser ES: Paternal age and risk of schizophrenia in adult offspring. Am J Psychiatry 2002, I59(9): I528-33.

19. Keskimäki I, Aro S: Accuracy of data on diagnoses, procedures and accidents in the Finnish Hospital Discharge Register. Int J Health Sci I99I, 2:I5-2I.

20. Pakaslahti A: On the diagnosis of schizophrenic psychoses in clinical practice. Psychiatria Fennica 1987, I 8:63-72.

21. Salokangas R: First-contact rate for schizophrenia in community psychiatric care. Consideration of the oestrogen hypothesis. Psychiatry Clinical Neurosci 1993, 242:337-346.

22. Isohanni M, Mäkikyrö T, Moring J, Räsänen P, Hakko H, Partanen U, Koiranen $M$, Jones $P$ : A comparison of clinical and research DSM-III-R diagnoses of schizophrenia in a Finnish national birth cohort. Social Psychiatry and Psychiatric Epidemiology 1997, 32:303-308.

23. Gauderman WJ, Kraft P: Biostatistical genetics and genetic epidemiology, Family-based case-control studies Chichester, England: Wiley \& Sons; 2002:267-275.

24. Sipilä $P$, Hartikainen $A L$, von Wendt $L, O j a ~ H:$ Changes in risk factors for unfavorable pregnancy outcome among singletons over twenty years. Acta Obstetricia et Gynecologica Scandinavica 1994, 73:612-618. 
25. Timonen S, Uotila U, Kuusisto P, Vara P, Lokki O: Effect of certain maternal, foetal and geographic factors on the weight and length of the newborn and on the duration of pregnancy. Annales Chirurgiae et Gynaecologiae Fenniae 1966, 55:196-213.

26. Cannon M, Jones PB, Murray RM: Obstetric complications and schizophrenia: historical and meta-analytic review. American Journal of Psychiatry 2002, I 59: I080-1092.

27. Westergaard T, Mortensen PB, Pedersen CB, Wohlfahrt J, Melbye M: Exposure to prenatal and childhood infections and the risk of schizophrenia: suggestions from a study of sibship characteristics and influenza prevalence. Archives of General Psychiatry 1999, 56( I I):993-8.

28. Brown AS, Schaefer CA, Wyatt RJ, Goetz R, Begg MD, Gorman JM, Susser ES: Maternal exposure to respiratory infections and adult schizophrenia spectrum disorders: a prospective birth cohort study. Schizophrenia Research 2000, 26:287-295.

29. Orvos H, Nyirati I, Hadju J, Pal A, Nyari T, Kovacs L: Is adolescent pregnancy associated with adverse perinatal outcome? Perinat Med 1999, 27:199-203.

30. Hemminki E, Gissler M: Births by younger and older mothers in a population with late and regulated childbearing: Finland I991. Acta Obstet Gynecol Scand 1996, 75:19-27.

31. Aleman A, Kahn R, J-P S: Sex differences in the risk of schizophrenia. Evidence from meta-analysis. Archives General Psychiatry 2003, 60:56I-57I.

32. Kendler KS, MacLean CJ: Estimating familial effects on the age at onset and liability to schizophrenia. Genetic Epidemiology 1990, 7:409-417.

33. Sham P, MacLean C, Kendler K: A typological model of schizophrenia based on the age at onset, sex and familial morbidity. Acta Psychiatrica Scandinavica 1994, 89:।35-|4I.

34. Suvisaari JM, Haukka J, Tanskanen A, Lönnqvist J: Age at onset and outcome in schizophrenia are related to the degree of familial loadings. Brit J Psych 1998, I 73:494-500.

35. Nicolson R, Brookner F, Lenane M, Gochman P, Ingraham L, Egan M, Kendler K, Pickar D, Weinberger D, Rapoport J: Parental schizophrenia spectrum disorders in childhood-onset and adultonset schizophrenia. American Journal of Psychiatry 2003, 1 60:490-495.

36. Kennedy J, Farrer L, Andreasen N, Mayeux R, St George-Hyslop P: The genetics of adult-onset neuropsychiatric disease: complexities and conundra. Science 2003, 302:822-826.

37. Cannon T, Kaprio J, Lönnqvist J, Huttunen M, Koskenvuo M: The genetic epidemiology of schizophrenia in a Finnish twin cohort. Archives General Psychiatry 1998, 55:67-74.

\section{Pre-publication history}

The pre-publication history for this paper can be accessed here:

http://www.biomedcentral.com/1471-244X/4/41/pre

pub

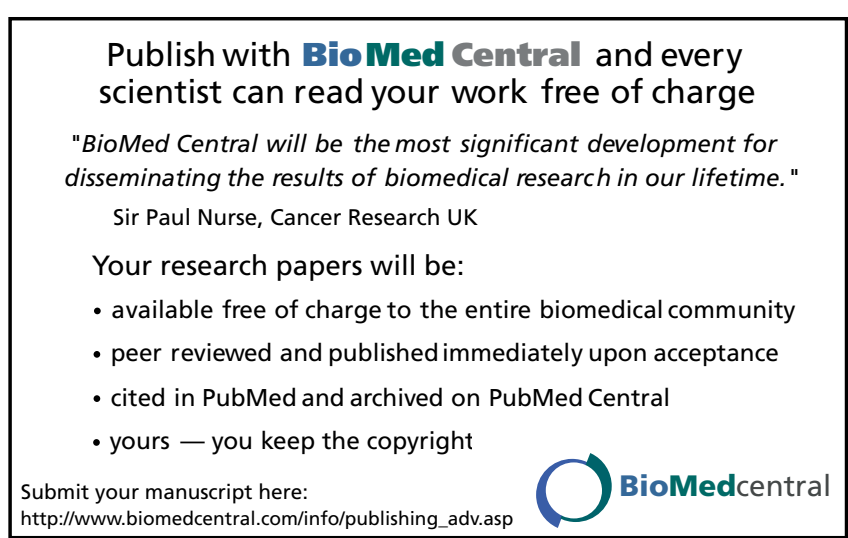

